\title{
Research on Humping Tendency in High Speed Laser Welding of SUS304 Austenitic Stainless Steel
}

\author{
Menglei Cai ${ }^{a}$, Chenhui $\mathrm{Wu}^{\mathrm{b}}$ and Xin $\mathrm{Gao}^{\mathrm{c}}$ \\ Wuhan Second Ship Design and Research Institute Wu Han 430000, China. \\ accaimenglei123@hust.edu.cn,b18502740804@16.3.com,c18813046254@163.com
}

\begin{abstract}
Keywords: 304 austenitic stainless steel, High speed laser welding, humping tendency, Process experiment, humping mechanism.
\end{abstract}

\begin{abstract}
In order to prevent humping defects in high speed laser welding, relationship between humping tendency and welding parameters such as laser power, welding speed and shielding gas blowing direction is studied in this paper. It is found that hump will appear periodically when the welding speed exceeds $21 \mathrm{~m} / \mathrm{min}$. humping tendency is not sensitive to the varieties of laser power but becoming obvious with the increase of the welding speed. The humping tendency is less obvious when gas blows backward instead of forward. The cross-section morphology characteristic of humping is observed. Rayleigh instability model is used to explain the forming mechanism of humping and the relationship between process parameters and humping tendency in high speed laser welding process. It is found that the potential mechanism of humping phenomenon is the break-up of liquid column due to surface tension. When the length-to-width ratio is less than $\pi$, humping can be suppressed. To raise the temperature of weld pool can prevent the liquid metal from cooling too fast and is good for liquid metal spreading, thus the humping is suppressed as well.
\end{abstract}

\section{Introduction}

The most direct way to improve the welding efficiency is to increase the welding speed. However, weld bead defects such as splash and undercut occurs when welding speed increases. And further increase of welding speed will lead to humping phenomenon. Hump can deteriorate weld morphology and undercut associated with humping phenomenon reduces the effective cross-sectional area of the joint. Stress concentration caused by undercut also reduces the ability of the joint to withstand dynamic loads. Hump is prevalent in arc welding, laser welding, electron beam welding, etc., which becomes a "bottleneck" of high speed welding [1-3].

Many research papers about the mechanism of hump have been published since 1968. Yamamoto et al. [4] proposed hydraulic jump model to explain humping phenomenon during GTAW. He considered that hydraulic jump occurred when molten metal wall jet velocity exceeded a critical value, thus led to humping. Mills and Keene [5] regarded Marangoni convection force as the reason for the humping phenomenon. Arc pressure model was firstly proposed by Paton et al. [6] who considered that a balance of pressure exists between arc and weld pool and hump occurred when arc pressure became larger than the metal pressure during SAW. Recently, Kumar and Debroy [7] have put forward Kelvin - Helmholtz instability model to explain humping phenomenon during GTAW. However, these models mentioned above are all used to explain the mechanism of humping in arc welding instead of laser welding. Pei et al. [8] considered that research results of humping in arc welding are not completely applicable to laser welding, because the molten pool geometry and the stress state of laser welding differs from that of arc welding. The pool of arc welding affected by arc force and momentum of the droplet, is shallow and wide. While the pool of laser welding, because of dynamic change of keyhole and metal vapor eruption, is deep and narrow. Pei et al. [9] used high-speed camera to observe the behavior of melt flow in high speed laser welding process. He found that humping formation underwent three stages: nucleation, growing up, solidification and he also proposed two measures to suppress the formation of hump. However, these studies failed to effectively reveal the mechanism of humping formation in high speed laser welding. Relationship 
between welding parameters and humping tendency requires further explanation as well. The laws of humping tendency and welding parameters in high speed bead welding of $0.6 \mathrm{~mm} 304$ austenitic stainless steel are studied in this thesis. Rayleigh instability model is used to explain the mechanism of humping formation and relationship between welding parameters and humping tendency. These works are very valuable to suppress the humping formation in high speed laser welding.

\section{Brief introduction to Hump}

Hump is periodic swelling of weld surface when welding speed exceeds a critical value. Scholars have conducted extensive researches on humping defects. They found that all humping defects could be classified into two forms: gouging region morphology (GRM) and beaded cylinder morphology (BCM) [10].

A typical GRM defect is shown in Fig.1.The weld is produced in GTAW process with large currents and high speeds. GRM morphology is characterized by open, unfilled dry spots alternating with hump. Meanwhile, there is a very large depression known as the gouging region in front of the weld pool and a trailing region, where a bulk of molten metal is stranded, in the back of the weld pool.

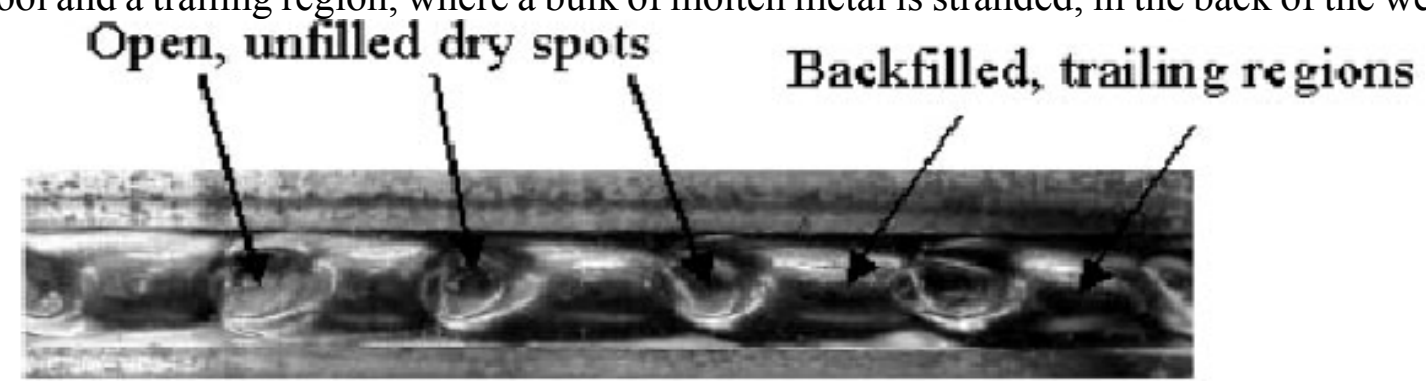

Fig.1 GRM during GTAW

BCM defects are shown in Fig.2. Obviously, this kind of hump is significantly different from GRM hump. There is no typical dry spots on BCM humping bead and no depressions below the specimen surface. The significant feature of BCM defects is beadlike protuberances which reside above the surface of the workpiece. The weld bead with BCM defect has a continuous undulating topography.

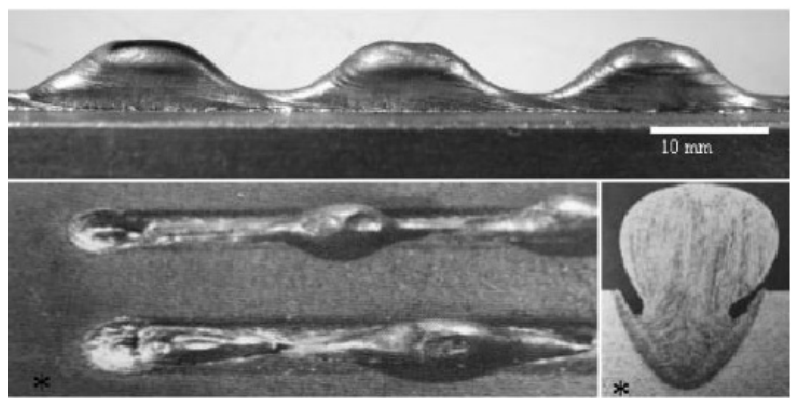

Fig.2 BCM defects: images marked with * are taken from Bradstreet [11]

\section{Experimental Materials and Methods}

The experiments were performed with a robotic laser welding system which includes one ABB IRB4400/60 robot and a IPG YLR-4000 fiber laser. The fiber laser delivers a maximum laser power of $4 \mathrm{~kW}$ and emits a wavelength of $1070 \mathrm{~nm}$ and the spot diameter is $0.3 \mathrm{~mm}$. The experimental materials are SUS304 austenitic stainless steel. Samples are all in the same dimension: $150 \mathrm{~mm} \times$ $75 \mathrm{~mm} \times 0.6 \mathrm{~mm}$. Before laser welding, acetone was used to wipe the surface of workpiece to eliminate the greasy dirt. Bead-on-plate weld method was used in this thesis. The shielding gas was $99.9 \%$ argon with a blowing angle of 45 degrees and a gas flow of $2.5 \mathrm{~m} 3 / \mathrm{h}$. As is shown in Fig. 3 , gas blowing forward means that laser is in front of shielding gas and gas blows from the back of the weld pool to the front of the weld pool. As is shown in Fig.4, gas blowing backward means shielding gas is in the front of laser and gas blows from the front of the weld pool to the back of the weld pool. The 
middle $7 \mathrm{~cm}$ of the weld was taken as the measurement region. Hump numbers of this region were counted and recorded. Besides, $1 \mathrm{~cm}$ of the weld was taken as a unit. Surface profile measuring instrument was used to measure the maximum height of the hump on a unit length.7groups of hump height were measured in each weld. The final hump height of weld was determined by the average height of the seven groups. 3 welds of same welding parameters were measured and the final result is determined by the average value of three welds. Humping tendency is evaluated by the hump number and hump height of measurement region.

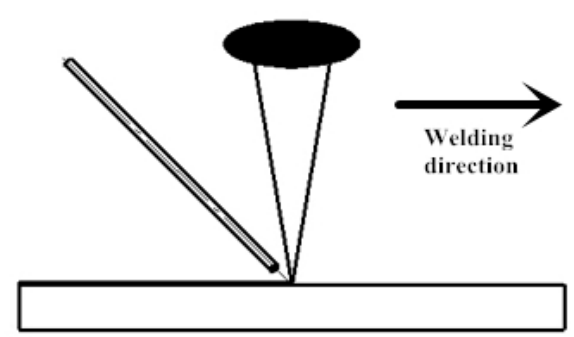

Fig.3 Gas blows forward

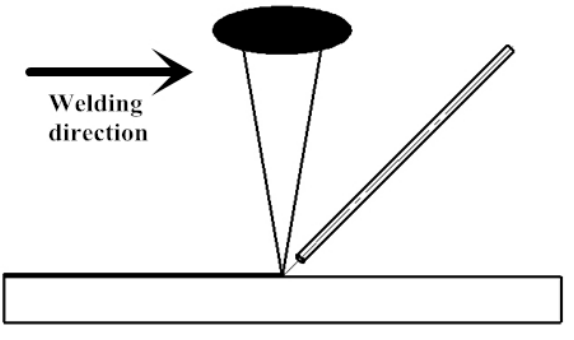

Fig.4 Gas blows backward

\section{Experiment Results}

\subsection{Relationship between Welding Parameters and Humping Tendency.}

As is seen in Fig. 5 and 6, no hump exists when welding speed is less than $21 \mathrm{~m} / \mathrm{min}$, whether the gas blows forward or backward. It can be seen in Fig.7 that, hump exists on weld surface when welding speed is greater than $21 \mathrm{~m} / \mathrm{min}$ with gas blowing forward. Nevertheless, by blowing gas backward and making use of reasonable laser power and welding speed, the hump can be wiped off (shown in Fig.8). However, if welding speed exceeds $25 \mathrm{~m} / \mathrm{min}$, hump can't be wiped off anyway (shown in Fig.9 and 10).

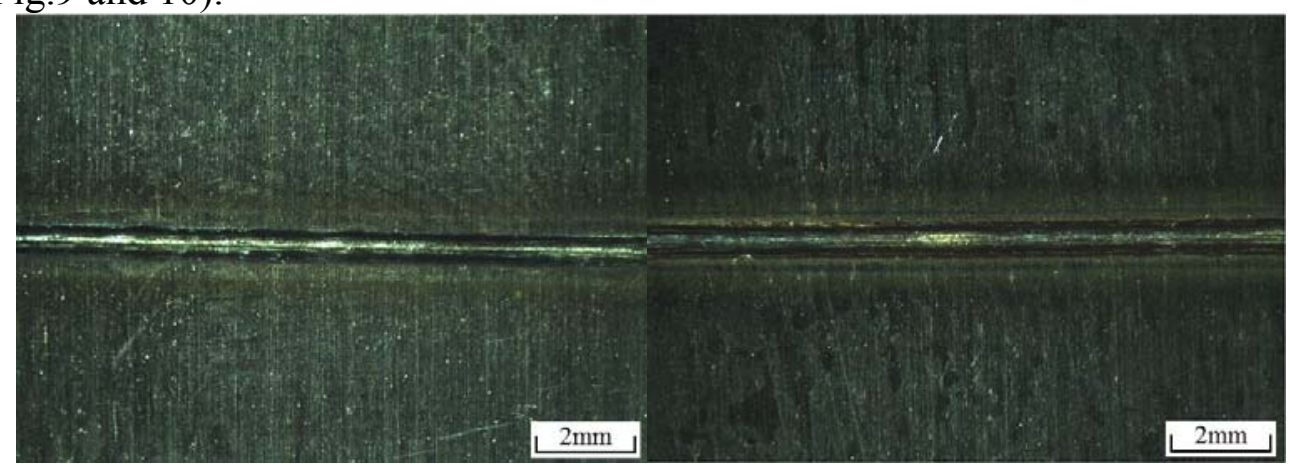

Fig. 5 Forward, $4 \mathrm{~kW}, 21 \mathrm{~m} / \mathrm{min}$

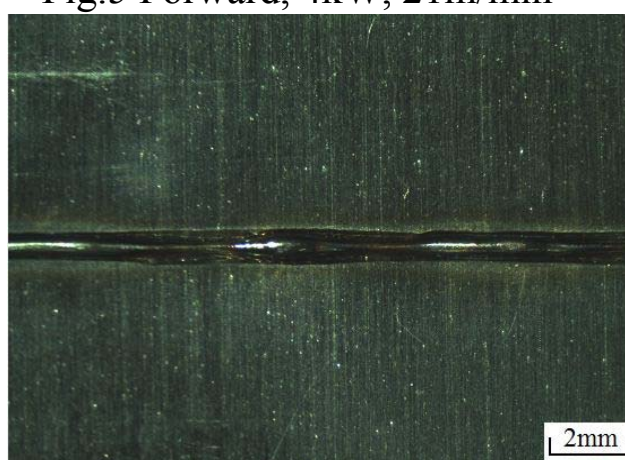

Fig.7 Forward, 4kW, 22m/min
Fig.6 Backward, 4kW, 21m/min

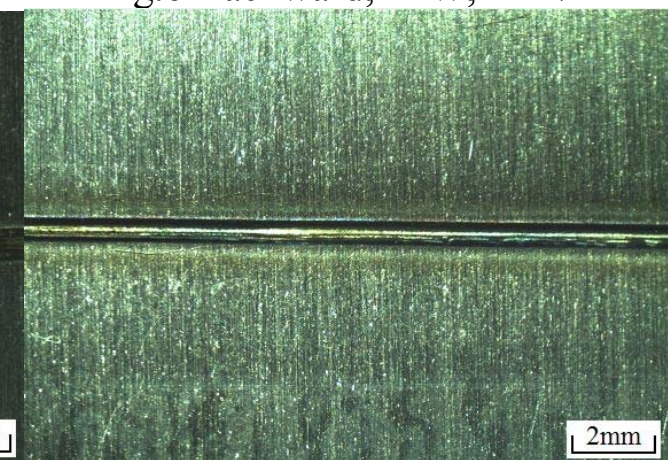

Fig. 8 Backward, 3.7kW, 22m/min 


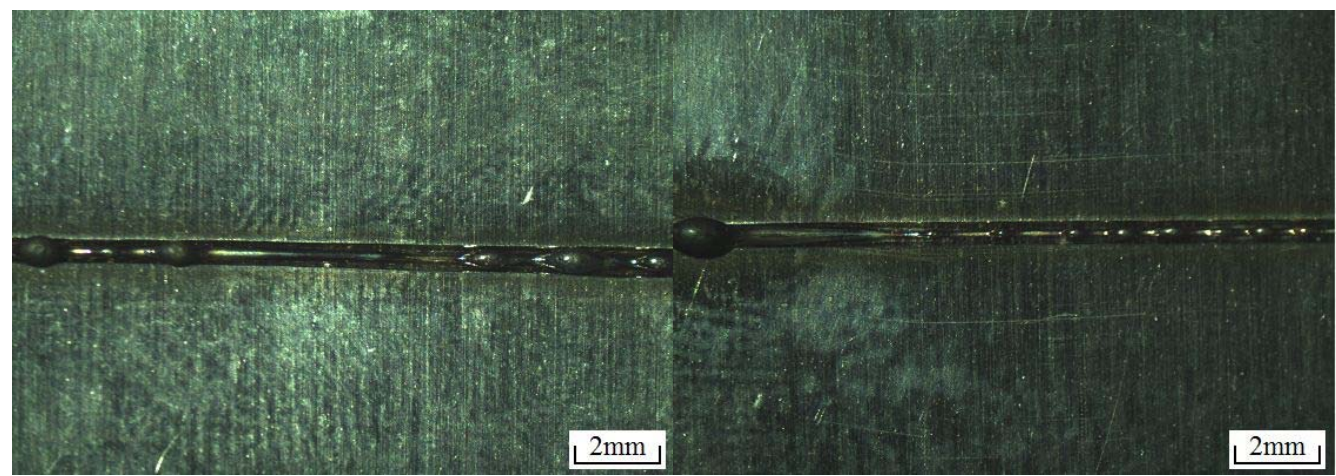

Fig.9 Forward, 4kW, 25m/min

Fig.10 Backward, 4kW, 25m/min

When welding speed is $25 \mathrm{~m} / \mathrm{min}$ using forward-blowing gas with the shielding gas sent in $45^{\circ}$ and the steel entirely penetrated, hump height and hump number are counted under different laser power (shown in Fig.11).As is seen, hump height and hump number vary little with the laser power.

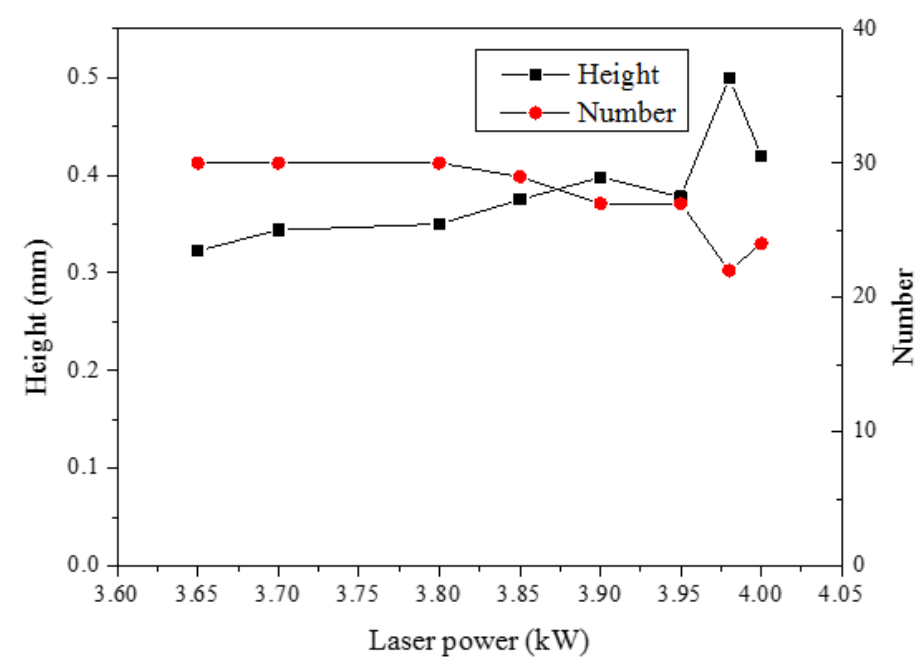

Fig. 11 humping tendency under different laser power at $25 \mathrm{~m} / \mathrm{min}$

In Fig.12, when laser power is $4 \mathrm{~kW}$, hump height and hump number are counted under different welding speed (over $21 \mathrm{~m} / \mathrm{min}$ ) with gas blowing forward. As is seen, hump tendency, represented by hump height and hump number, increases with the increasing of welding speed

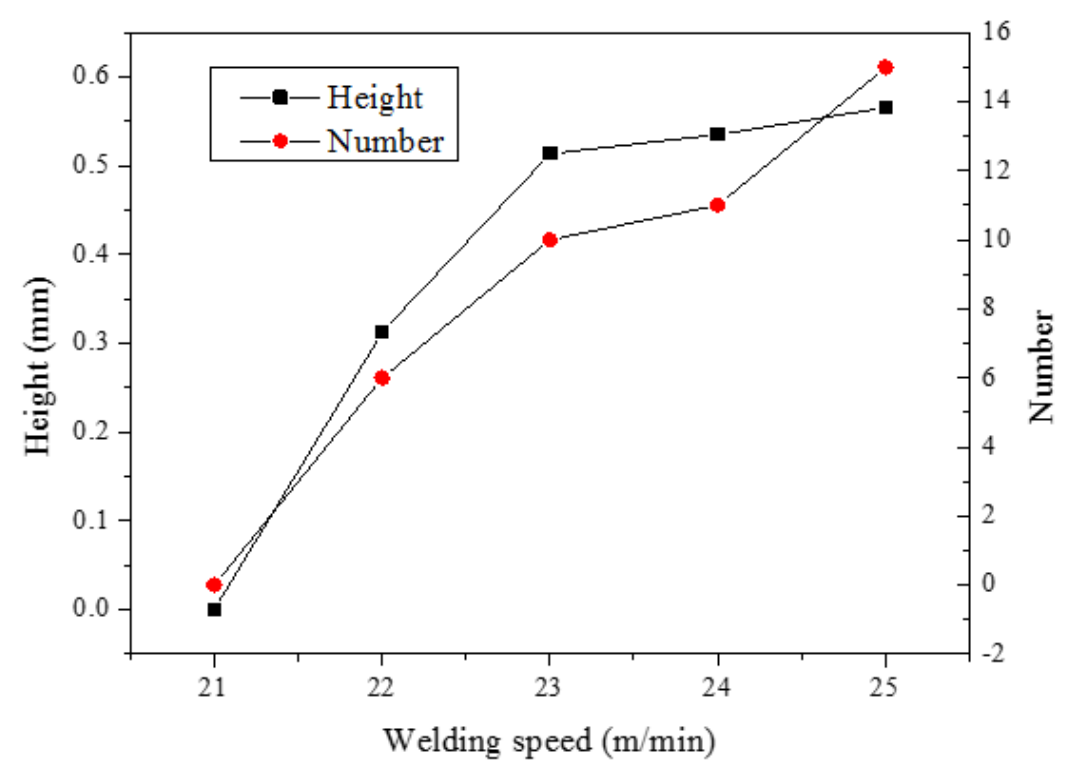

Fig.12 humping tendency under different welding speed at 4kW 
In Fig.13, when the laser power is $4 \mathrm{~kW}$, hump number is counted under different welding speed (over $21 \mathrm{~m} / \mathrm{min}$ ) with gas blowing forward and backward. As is seen, hump tendency is less obvious when gas blows backward, i.e., with the same welding speed and laser power, hump number is lower when gas blows backward compared with gas blowing forward.

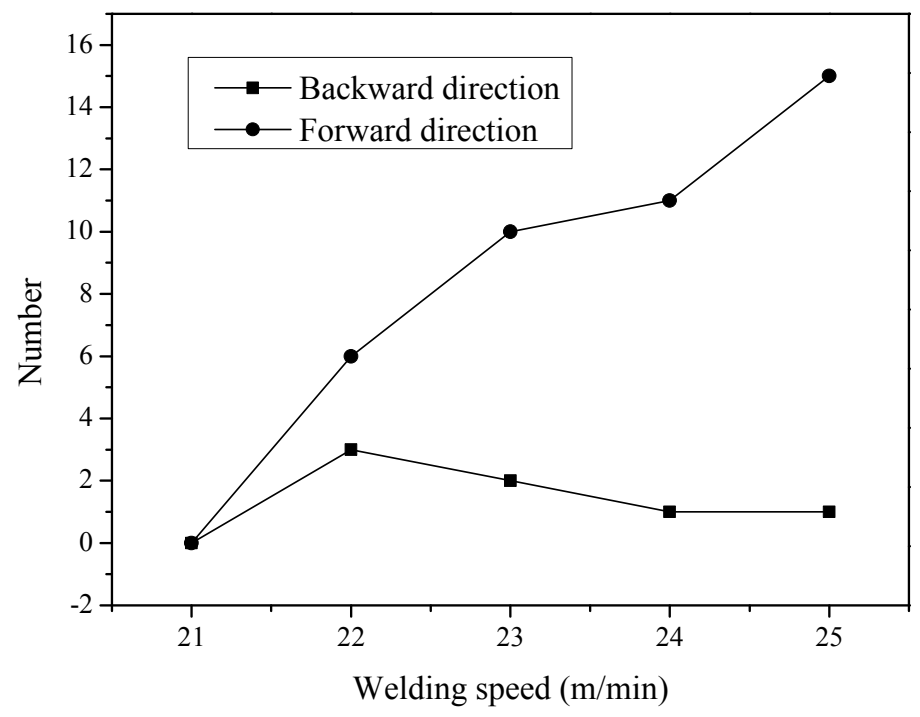

Fig.13 humping tendency when gas blows in different directions

\subsection{Features of Humping Cross-section Morphology}

As is seen in Fig.14, the samples were cut using a line cut machine. All samples were shaped using different types of sand paper, then polished and etched with solutions including $10 \% \mathrm{HF}$ mixed with $20 \%$ HNO3and $70 \% \mathrm{H} 2 \mathrm{O}$. Fig. 15 was obtained when the sample was observed with metallographic microscope.

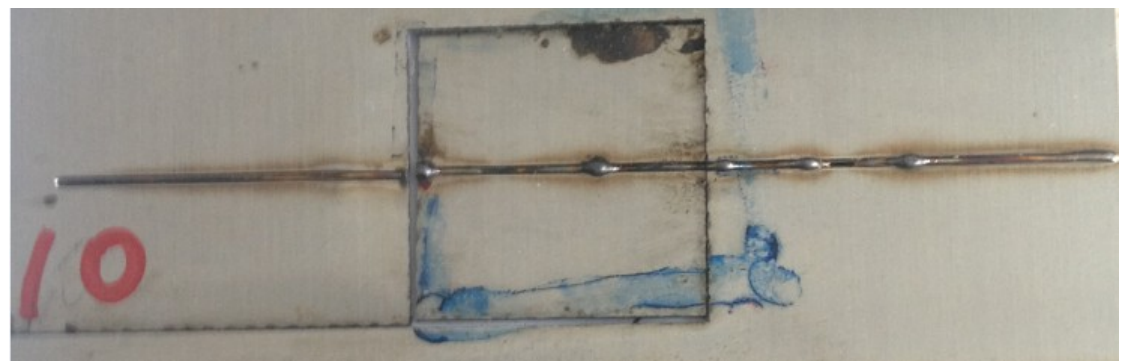

Fig.14 The cutting position of hump (backward direction, $3.9 \mathrm{~kW}, 23 \mathrm{~m} / \mathrm{min}$ )

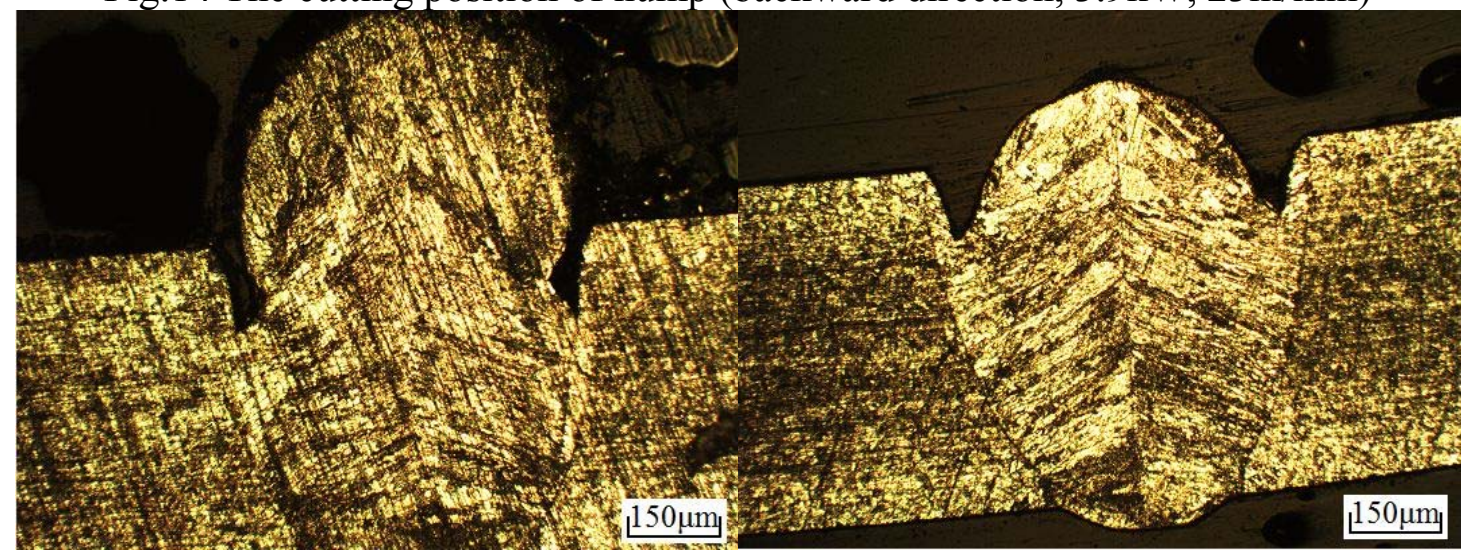

Fig. 15 Cross-section of peak and cross-section of valley

As is seen in Fig.14 and Fig.15, the features of the cross-section morphology of hump in high speed laser welding are listed as follows:

(1)The humping weld mentioned in this thesis belongs to BCM humping weld.

(2)Peak and valley of humping weld are accompanied with serious undercut. 
(3)The fusion line of peak and valley in one humping weld is roughly same. Thus, the depth-to-width ratio of weld is basically a fixed value for one welding condition, although the surface morphology of humping weld is undulating.

(4)At the peak of humping weld, the amount of melting metal is larger. The cross-section of peak is approximately circular and has no direct contact with base metal. Therefore, it is surface tension of liquid metal that keeps the circular part during welding process. The amount of melting metal at the valley of humping weld is smaller while still larger than that of the base material. The cross-section of valley has a parabolic shape.

Fig. 16 is a cross-section of humping weld obtained through metallographic microscope. Based on grain growth direction, the cross-section of humping weld can be divided into two regions. Region one is in contact with base material. As a result, this region has a high thermal conductivity and fast cooling rate. Therefore, melting metal of this region solidifies first. Columnar crystals in region one grow from the edge of weld zone to the center of it. The growth direction is approximately perpendicular to the fusion line. Region two is the top of the hump, which is in contact with air. Therefore, the cooling rate is smaller than that of region one and melting metal in this region solidifies later. The grain in this region grows upwardly, perpendicular to the solidification boundary of region one.

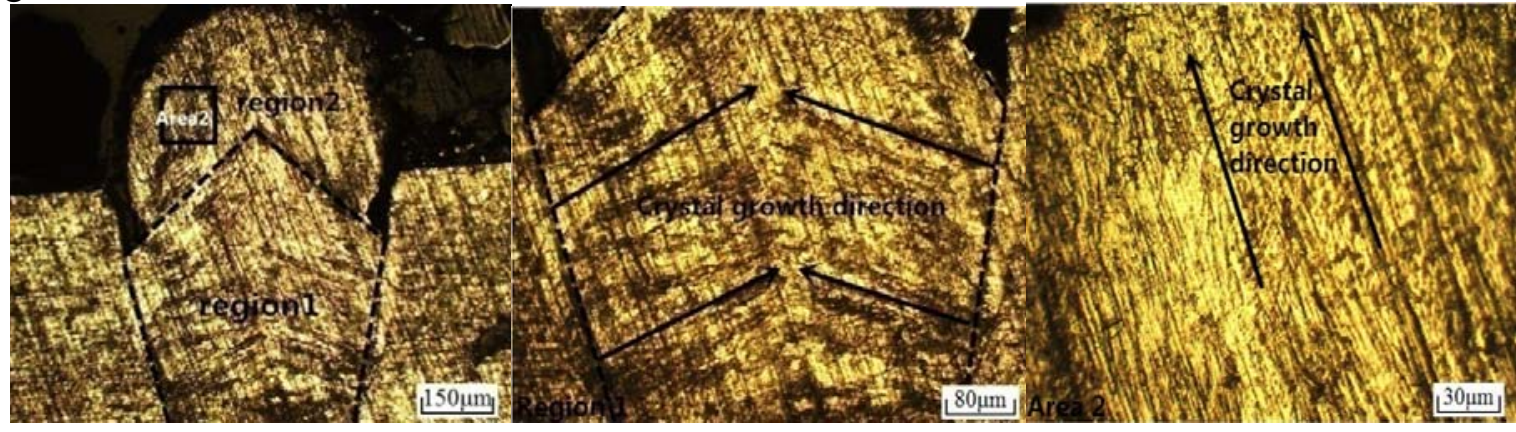

Fig.16 Cross-section morphology of humping weld

\section{Analysis \&Discussion}

In this thesis, Rayleigh free cylinder instability model is used to explain humping phenomenon. We take the point of view that a small diameter liquid cylinder suspended in free space is unstable and will break up into a serious of droplets. In general, the forces acting on the weld pool are surface tension and gravity. Gratzke[12] analyzed the influence of gravity on weld pool and considered that gravity was negligible in laser welding. We assume that molten metal forms a liquid cylinder and suspend freely in space under the effect of surface tension. When disturbances happen, the liquid cylinder will break up into individual drops to minimize surface tension. In Fig.17, R is the radius of the liquid cylinder, and $\lambda$ is the length of the side of liquid cylinder. When $\lambda$ exceeds the circumference of the cylinder $2 \pi R[13]$, instability occurs and the cylinder will break up into droplets eventually. Furthermore, when $\lambda$ equals $2.9 \pi R[14]$, instability grows the fastest. As the welding process goes on, new swelling or hump take shape once the liquid cylinder reaches the critical length $2 \pi \mathrm{R}$.

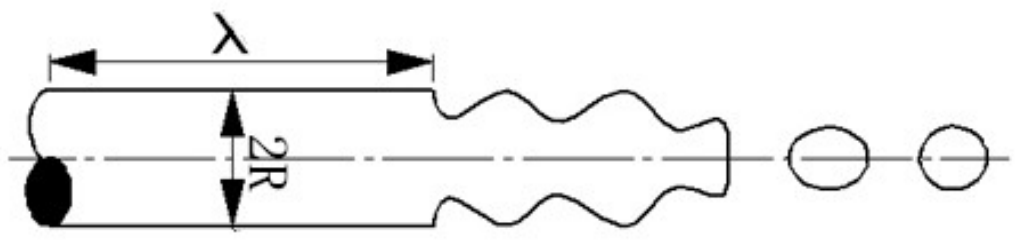

Fig.17 Rayleigh instability model

With the increase of weld speed, $\lambda$ becomes longer, $\mathrm{R}$ becomes smaller and the welding bead becomes long and narrow. According to Rayleigh instability theory, the larger length-to-width ratio 
of weld pool is, the more unstable it is. So the faster welding speed is, the more obvious humping tendency is. Pei et al.[15] observed that the length of weld pool increases with the increase of welding speed(shown in Fig.18). Because the angle between metal vapor ejecting direction and pool surface is reduced when welding speed improves, the horizontal component of momentum from metal vapor on the rear of keyhole increases. Consequently, the flowing distances of liquid metal increase as the force driving liquid metal to the weld pool tail improves (shown in Fig.19).
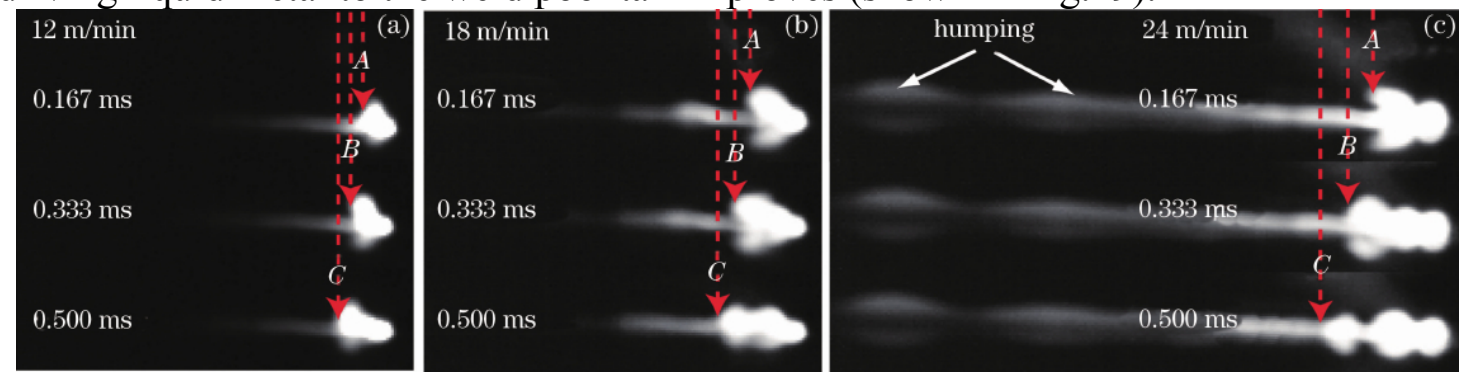

Fig.18 The flowing behavior of weld pool under different welding speed [13]
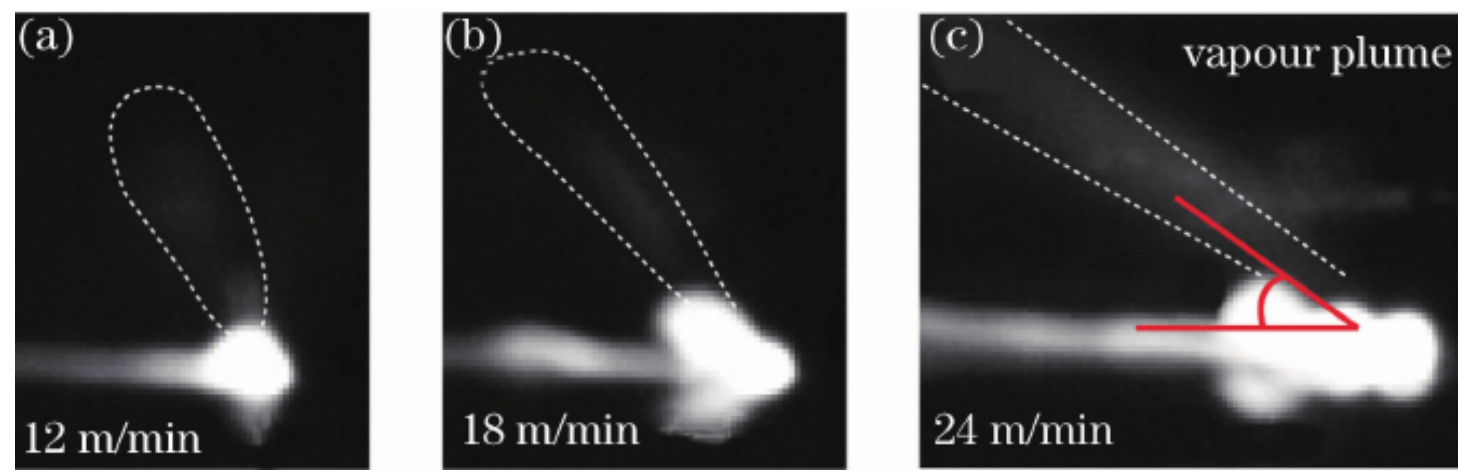

Fig.19 The ejecting angle of metal vapor under different welding speed [13]

As is seen in Fig.20, when shielding gas blows forward, it blows to the tail of weld pool. Then the weld pool is disturbed and liquid metal cylinder becomes easier to be unstable. Besides, the temperature of liquid metal in weld pool is decreased when shielding gas blows forward. As a result, the metal in the tail of weld pool solidifies faster. The solidified metal prevents liquid metal from flowing to the tail of weld pool and liquid metal stacks in front of the solidified metal to form the hump. These two factors lead to the increase of humping tendency. In Fig.21, when shielding gas blows backward, it blows to the cold metal in the front of the weld pool. Consequently, weld pool is protected from disturbing. Besides, liquid metal behind the keyhole won't be cooled down too fast by shielding gas. The solidification rate of liquid metal is reduced, so the liquid metal has a longer time to spread. Thereby, the formation of hump is inhibited.
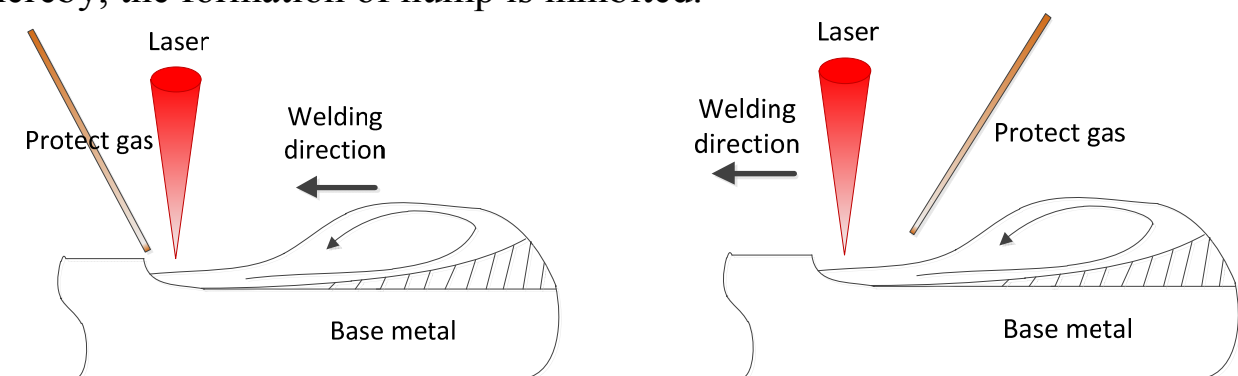

Fig.20 Weld pool situation with gas blowing forward Fig.21 Weld pool situation with gas blowing backward

\section{Summary}

(1) When the welding speed is larger than $21 \mathrm{~m} / \mathrm{min}$, hump will occur periodically at the bead and humping tendency is not sensitive to changes of laser power while becomes obvious with the increase 
of the welding speed. The humping tendency under backward-blowing gas is less obvious compared with forward-blowing gas.

(2) The potential mechanism of humping phenomenon is the break-up of the liquid column under the action of surface tension. The length-to-width ratio of weld pool can be monitored to avoid the formation of hump. In other words, when the length-to width ratio is less than $\pi$, hump can be suppressed. For example, increasing the diameter of the spot can reduce the humping tendency.

(3) Increasing the temperature of weld pool can prevent the liquid metal from cooling too fast and is good for the spread of liquid metal, as a result, humping is suppressed.

\section{References}

[1]. Bengtsson P. (1992) High productivity MIG/MAG welding processes. Welding and Metal Fabrication,60(6): 226-228.

[2]. Feng L, Cheng S J, Yin S Y. (1999) Mechanism of undercut phenomenon in high speed welding. HanJieXueBao, (1):22-30

[3]. Ye D J, Hua X M, Lv Y L.( 2011) Formation mechanism of humping at high speed welding.Hot Working Technology,40(11): 148-151.

[4]. T.Yamamoto and W.Shimada.(1975)A study on bead formation in high speed TIG arc welding at low gas pressure. Proc. Advanced Welding Technology-2nd Int.Symp.of the Japan Welding Soc. on 'Advanced Welding Technology, 'Osaka, Japan. Japan Welding Society, Paper 2-2-(7).

[5]. K. C. Mills and B. J. Keene.(1990)Factors affecting variable weld penetration. International Material Review,35(4), 185-216.

[6]. E. O. Paton, S. L. Mandel'berg and B. G. (1971)Sidorenko: Autom. Weld. 24(8), 1-6.

[7]. A. Kumar and T. Debroy.(2006)Toward a unified model to prevent humping defects in gas tungsten arc welding. Welding Journal:292-304

[8]. Pei Y L,Shan J G,Ren J L.(2012)Study of humping tendency and affecting factors in high speed laser welding of stainless steel sheet. Acta Metall Sin,48:1431

[9]. Pei Y L,Shan J G,Ren J L. (2013)Investigation of humping formation based on melt flow analysis in high-speed laser welding process. Acta Metall Sin,49(6): 725-730.

[10]. Soderstrom E,Mendez P. (2006)Humping mechanisms present in high speed welding . Science and Technology of Welding and Joining, 11(5):572-579

[11]. Bradstreet B J. (1968) Effect of surface tension and metal flow on weld bead formation. Welding Journal, 47(6):314-322

[12]. Gratzke U, Kapadia P D, Dowden J, et al. (1992) Theoretical approach to the humping phenomenon in welding processes. Journal of Physics D: Applied Physics, 25(11): 1640.

[13]. Lord Rayleigh.(1877)Theory of sound, Vol. 2, New York, Dover Publications.

[14]. J. N. Anno.( 1977)The mechanics of liquid jets. Toronto, Lexington Books.

[15]. Pei Y L,Shan J G,Ren J L.( 2013) Effect of welding speed on melt flow behavior in high speed laser welding process. Chinese Journal of Lasers, 40(5): 0503001-5. 